UDK 528.721.221.6

\title{
TERRESTRIAL LASER SCANNING ASSESSMENT OF GENERALIZATION ERRORS IN CONVENTIONAL TOPOGRAPHIC SURVEYS
}

\author{
Martin SOBAK ${ }^{1}$, Artu ELLMANN ${ }^{2}$, Tarvo MILL ${ }^{3}$ \\ ${ }^{1}$ Engineering surveying enterprise Geo. S.T. OÜ, Laki 15, 12915 Tallinn, Estonia \\ 2, 3 Faculty of Civil Engineering, Tallinn University of Technology, Ehitajate rd. 5, 19086 Tallinn, Estonia \\ E-mails: ${ }^{1}$ martinsobak@gmail.com (corresponding author), ${ }^{2}$ artu.ellmann@ttu.ee, ${ }^{3}$ tarvo@tktk.ee
}

Received 15 January 2015; accepted 9 March 2015

\begin{abstract}
The technology of terrestrial laser scanning has widely been used in the surveying industry in recent years due to higher data collecting productivity compared to traditional tacheometric survey. The aim of this study is to assess generalization errors in topographic surveys of landforms on the basis of a large vegetation free semi-coke landfill hill with the relative height of $116 \mathrm{~m}$ in North-East Estonia. The numerical assessment of errors is proceeded by comparing a high-resolution terrestrial laser scanning (TLS) 3D surface model with surface models generated from the sparser data steps $(10,20,30$ and $50 \mathrm{~m})$. The 10 and $20 \mathrm{~m}$ data step surface models yield discrepancies within $\pm 20 \mathrm{~cm}$. The $30 \mathrm{~m}$ data step models revealed slightly larger differences. Expectedly the largest elevation differences reaching up to $2.5 \mathrm{~m}$ were associated with the $50 \mathrm{~m}$ point step.
\end{abstract}

Keywords: digital surface model (DSM), point cloud, tacheometry, GNSS survey, semi-coke landfill, surveying regulations.

\section{Introduction}

3D surface models are used in various areas for several different purposes such as volume computation, vertical planning and in landscape design. In addition, 3D surface models can also be used to solve problems involving engineering of facilities.

Traditionally 3D surface models are compiled from topographic survey data acquired by conventional tacheometric or global navigation satellite system (GNSS) surveys. Even though terrestrial laser scanning (TLS) is widely used for surveying of buildings (Murphy et al. 2011; Mill et al. 2013), technical infrastructure (Fekete et al. 2010; Nuttens et al. 2010) and in monitoring of structural deformations (Wang et al. 2009; Mill et al. 2014, 2015), this novel technique (alongside with airborne laser scanning - ALS) can also be used for acquiring topographic data. A study by Pirotti et al. (2013) analyses the use of TLS and ALS in high resolution topography surveys in terms of factors influencing the positional accuracy, range, point density and quality. A comprehensive overview of both TLS and ALS is given in Vosselman and Maas (2009). In addition Baltsavias (1999) provides basic relations and formulas concerning TLS and ALS. The benefits of TLS and ALS are mainly due to the data collecting speed that can vary from few thousands up to million points per second resulting in a high resolution dataset also known as a point cloud. An obvious drawback is that the signal of most terrestrial laser scanners is unable to penetrate through vegetation and thus the reflected signal cannot be surely linked to the ground surface.

High-resolution surveying of large areas using conventional tacheometric or GNSS surveys can be very time consuming (thus also expensive) primarily depending on the landscape features. Since every geodetic survey method has its own advantages/shortages and depending also on the purpose of the surface model the most suitable method should be chosen. Therefore it is vital to acknowledge the differences in $3 \mathrm{D}$ surface models resulting from different source data. 3D surface models created from TLS, ALS, GNSS and tacheometric survey data have previously been compared by e.g. Gallay et al. (2012). Naumann et al. (2013) gives an accuracy estimate of digital surface models (DEM) created by unmanned aerial systems and TLS. 


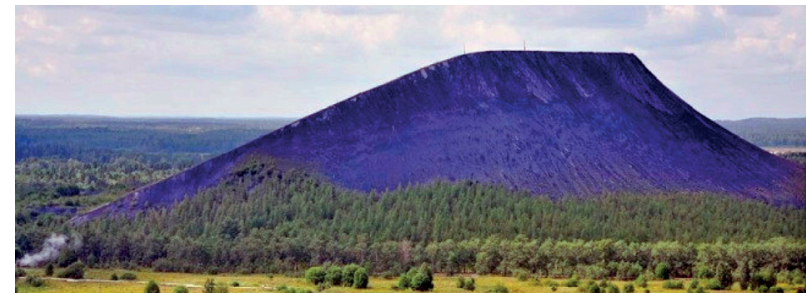

Fig. 1. Kiviõli semi-coke hill in original shape before the flattening, view from East (photo was taken in August 2009, Lempzi pildiblog 2014)

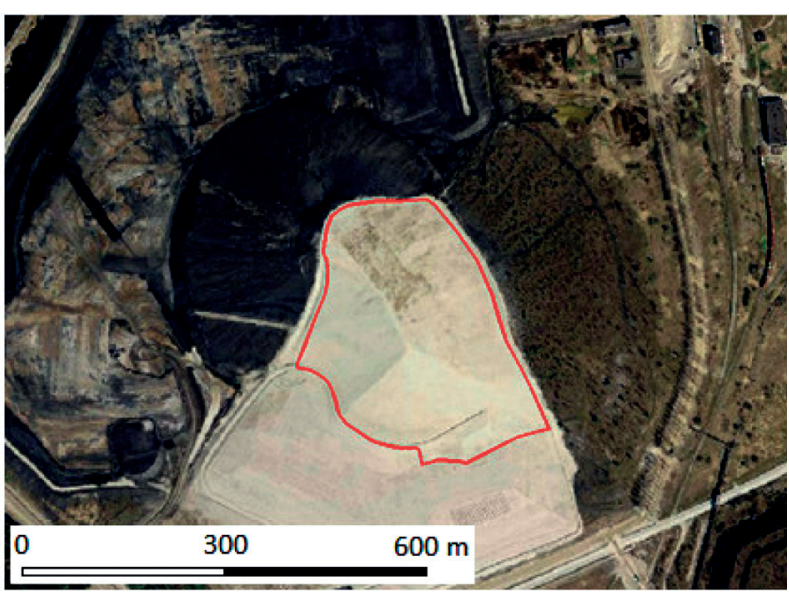

Fig. 2. The TLS-survey area (outlined by the red line) on the top part of the Kiviõli semi-coke hill (Ortophoto, Estonian National Land Board 2014)

The accuracy of resulting 3D models depends primarily on many aspects: the accuracy of survey data; the resolution of survey data; and also methods of data processing (e.g. Julge et al. 2014) and modelling. Also constraints set by national surveying standards and regulations affect the surveying resolution and productivity. For instance, according to Estonian national survey standards (Surveying regulation 2007) at the compilation of a most common topographic plan in scale of 1:500 the allowable distance between survey points should not exceed 20 meters. Smaller scales like 1:1000 and 1:2000 are only used in specific cases such as mapping disperse settlements or for small scale land planning. The largest distance between survey points at these scales is determined not to exceed 30 and 50 meters, respectively. The allowable heighting errors are also associated to the selected plane scales, being 10,15 and $20 \mathrm{~cm}$ for scales of 1:500, 1:1000 and 1:2000, respectively (Surveying regulation 2007).

The present study compares surface models created from TLS data with the aim to assess generalization errors in conventional topographic surveys of landforms. For this purpose the initial high-resolution TLS data acquired over a sizeable vegetation-free landform were artificially thinned to create sparser point clouds imitating realistic conventional tacheometric or GNSS surveys. The objective of this research is to compare the surface models created from point clouds with different data step and assess empirically the corresponding generalization errors that may occur during conventional topographical surveys.

The aforementioned goals are tackled through a case study, which is performed on a large vegetationfree landform. Its main characteristics are reviewed in Section 1. The second section gives an overview of the TLS equipment used and corresponding fieldwork. The third section describes the TLS data post processing, whereas the fourth section gives an overview of the results, their comparisons and verifications. A brief summary concludes the paper.

\section{The case study}

\section{General description of the study area}

An industrial waste and semi-coke landfill hill (in further text also to be simply referred as "ash-hill", see also Fig. 1) with the relative height of $116 \mathrm{~m}$ (Pae et al. 2005) is located in North-East Estonia, near the town of Kiviõli.

The shape of this abandoned ash-hill was redesigned in order to reduce the environmental hazards. After obtaining the designed shape the ash-hill was to be covered with a layer of bentonite mats and a layer of geosynthetic drainage mats. Finally, a protective vegetation layer with the thickness of $40 \mathrm{~cm}$ (grassy areas) and $80 \mathrm{~cm}$ (forested areas) was to be laid on top. In addition, rainwater collection ditches and collecting pools were excavated. (Jürgens 2011)

The TLS survey was proceeded over the upper part (with an area of 7.2 ha) of the ash-hill (Fig. 2). By the beginning of the TLS survey the upper part of the ash-hill was somewhat flattened from the original shape of a sharp-edged hump (see Fig. 2). The slopes were evened out, whereas the maximum elevation differences at the time of TLS measurements did not exceed 70 meters. Importantly, and most relevantly to the present study, the TLS survey area was completely vegetation-free. The actual aim of the TLS survey was to compile a precise 3D model of the top part of the ash-hill, in order to verify correspondence to the design plan and estimate the amount of remaining earthworks (fill and cut). The requested density of the point cloud was 2 points per square meter. The TLS survey was carried out by an Estonian surveying enterprise Geo S.T. OÜ in spring 2012. 


\section{Terrestrial laser scanning}

\subsection{The used equipment}

The TLS data used in this study were acquired by using the Leica ScanStation C10 (Fig. 3) laser scanner, which utilizes the so-called Time-of-Flight measuring principles. According to the technical specifications of the used scanner the maximum measuring range is $300 \mathrm{~m}$, a $360 \times 270^{\circ}$ field of view (FoV) and maximum scanning rate of up to 50,000 points/sec. According to manufacturer's specifications the scanner's accuracy of a single measurement is $\pm 6 \mathrm{~mm}$ in position and $\pm 4 \mathrm{~mm}$ in distance (valid for the $1 \mathrm{~m}-50 \mathrm{~m}$ range). The scanner is also equipped with a digital photo camera that enables assigning true RGB values during the postprocessing to survey points.

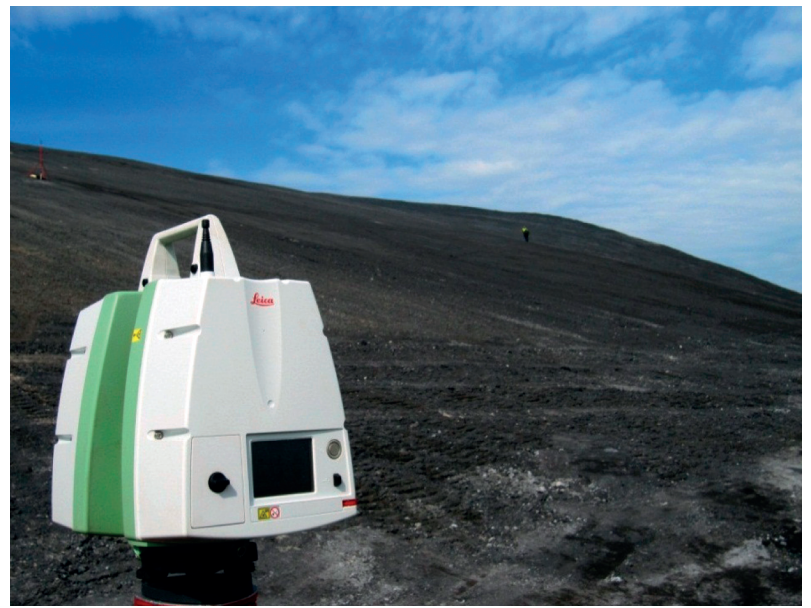

Fig. 3. The used TLS device during the course of the survey (Geo S.T. OÜ 2012)

a)

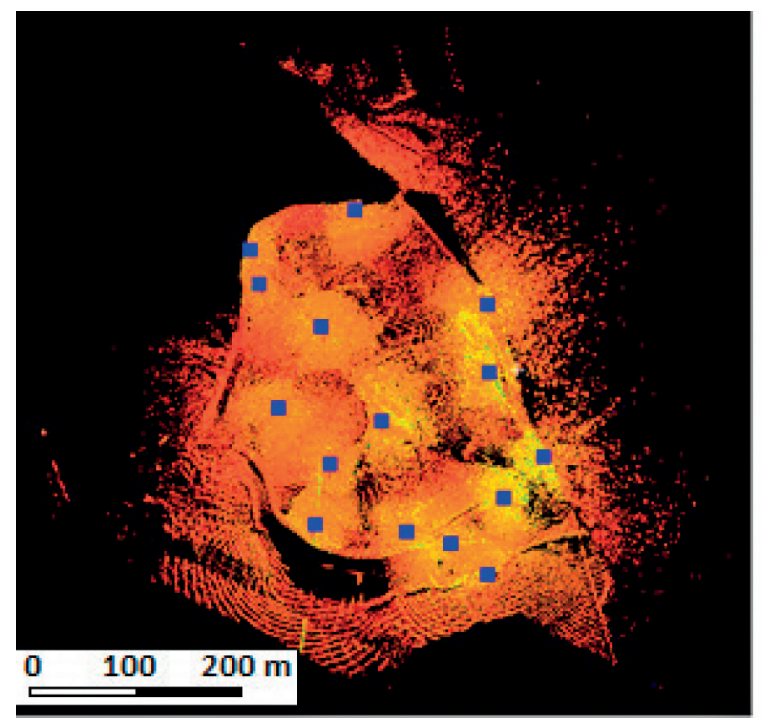

The acquired data forms a point cloud of $n$ observations where each point holds $3 \mathrm{D}$ coordinates $\left(x_{i}, y_{i}, z_{i}\right), \quad i=1, \ldots, n$ in the scanner's intrinsic coordinate system. The scanners intrinsic coordinates of the survey points are computed from the measured spherical polar coordinates as follows:

$$
\left[\begin{array}{c}
x_{i} \\
y_{i} \\
z_{i}
\end{array}\right]=\left[\begin{array}{c}
r_{i} \cos \varphi_{i} \cos \theta_{i} \\
r_{i} \sin \varphi_{i} \cos \theta_{i} \\
r_{i} \sin \theta_{i}
\end{array}\right],
$$

where $\theta_{i}$ and $\varphi_{i}$ are the measured vertical and horizontal angles of point $i, r_{i}$ is measured distance of an $i$-th point.

Targets observed from neighbouring TLS stations allow transforming neighbouring point clouds into one common coordinate system (also known as registering), thus forming also a joint point cloud.

For transformation of the local coordinates $\left(x_{i}, y_{i}, z_{i}\right)$ of an individual $i$-th survey point into extrinsic (e.g. national) coordinate system $\left(x_{i}^{E}, y_{i}^{E}, z_{i}^{E}\right)$ the coordinates of these targets need to be determined in the extrinsic coordinate system.

\subsection{Field work}

A total of 15 TLS stations were established for scanning the entire study area (Fig. 4a), i.e. each TLS station covered $\sim 0.5$ ha (+ overlapping). Since the scanning was conducted on hill slopes, the direct line of sight between the high definition scanning (HDS) targets mounted at the top side of the hill was rather limited (see Fig. 4b). The mounted three HDS targets were

b)

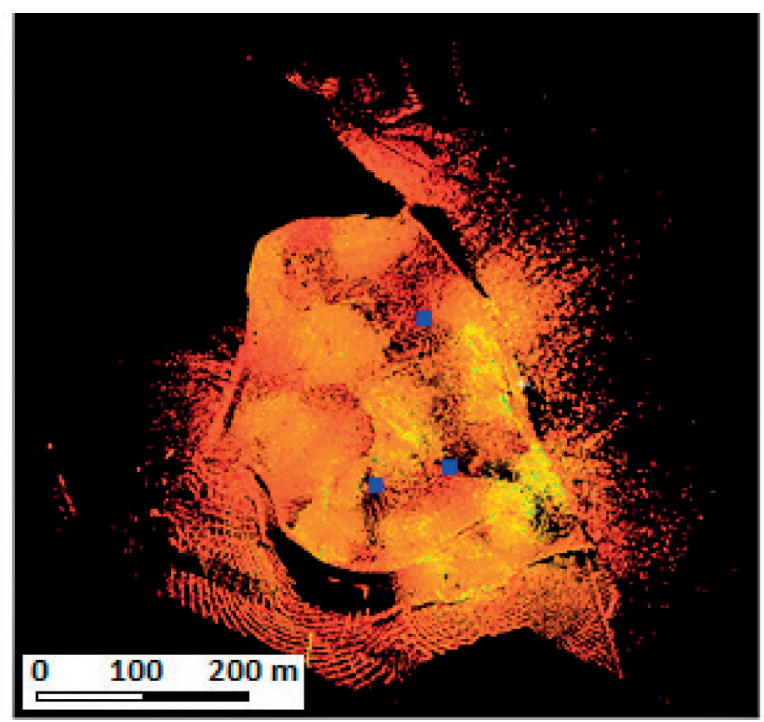

Fig. 4. The placement of scanning stations and HDS targets on the semi-coke landfill where a) TLS scanning stations; b) high definition scanning targets. Both are presented as blue squares placed on the TLS point cloud (visualised via the TLS signal intensity values) 
previously coordinated by using the Estonian national map projection rectangular coordinates (L-EST97) and the Baltic Height System 1977 by tacheometry using national control points located on the foot of the ashhill. These coordinated targets were used to transform the TLS point clouds into the L-EST97 rectangular coordinates. The scanner was oriented by using either: (i) resection or (ii) setting the instrument on a known point and backsighting. (see Fig. 5).

\section{TLS data post processing}

The TLS data processing was conducted by using Leica Geosystems AG Leica Cyclone ver. 7.3 and Autodesk Autocad Civil 3D 2013 software packages. The initial registering and cleaning of point clouds, as well as thinning point clouds, were done with the Leica Cyclone software. Autocad Civil 3D package was used to create and compare the resulting surface models.

The joint TLS point cloud was thinned using four different data steps $(10,20,30$ and $50 \mathrm{~m})$ in order to imitate tacheometric or GNSS survey. Therefore also breakpoints of landscape (such as the top and the foot of the hill cf. Fig. 6) were added manually, since these are routinely measured during the course of any actual topographic survey. The corresponding statistics of the resulting grids is provided in Table 1.

Table 1. The amount of data-points used in comparisons

\begin{tabular}{|l|c|c|c|c|c|}
\hline & $\begin{array}{c}\text { Cleaned } \\
\text { TLS point } \\
\text { cloud }\end{array}$ & \multicolumn{4}{|c|}{$\begin{array}{c}\text { Thinned point clouds (including } \\
\text { breakpoints) }\end{array}$} \\
\hline $\begin{array}{l}\text { Average } \\
\text { steps } \\
\text { between } \\
\text { points [m] }\end{array}$ & 0.5 & 10 & 20 & 30 & 50 \\
\hline $\begin{array}{l}\text { No. of } \\
\text { points }\end{array}$ & 133311 & 1178 & 420 & 305 & 173 \\
\hline $\begin{array}{l}\text { Ratio of } \\
\text { retained } \\
\text { points [\%] }\end{array}$ & 100 & 0.88 & 0.32 & 0.23 & 0.13 \\
\hline
\end{tabular}

The vegetation-free landscape allows collecting data without any significant "noise" and therefore makes the TLS-based surface model an ideal reference for assessing topographic surveys. A comparison of resulting surface models was carried out for determining elevation and volume differences. The detected discrepancies are expressed also via surface profiles at selected locations (e.g. those intersecting areas of largest elevation discrepancies, see Section 4.2).

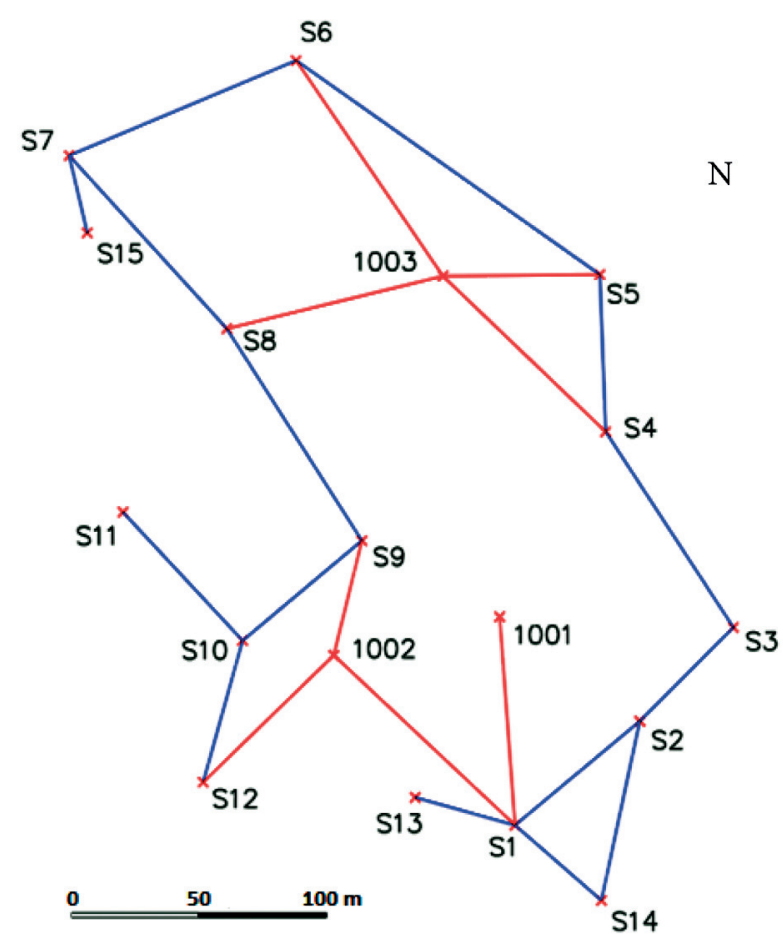

Fig. 5. The survey network in the semi-coke landfill ash-hill. Notes: S1 to S15 denote locations of TLS survey stations, whereas 1001 to 1003 denote locations of the HDS targets. Blue lines indicate orientation measurements between TLS survey stations. The red lines indicate scanning sights towards HDS targets.

\section{Results}

\subsection{Compilation and comparisons of 3D surface} models

The actual terrain surface consists of an infinite amount of irregular terrain elements. The height values within the areas between the survey points are usually obtained by an interpolation method. In general, interpolation techniques are based on the principles of spatial autocorrelation, which assumes that closer points are more similar compared to farther ones. There are various methods of interpolation such as Inverse Distance Weighting (IDW), local polynomial, Nearest Neighbour (NN), and Radial Basis Functions (RBFs). Hence, different interpolation methods can result in different results over the same data (Arun 2013). In order to represent the measured surface, e.g. for engineering design purposes, a digital surface model is created. In general, there are two common methods of presenting a surface; $(i)$ a raster digital elevation model (DEM), and (ii) a triangulated irregular network (TIN) model, both can be created by using tacheometric and GNSS survey data, TLS data, aerial photographs and topographic maps. 
a)

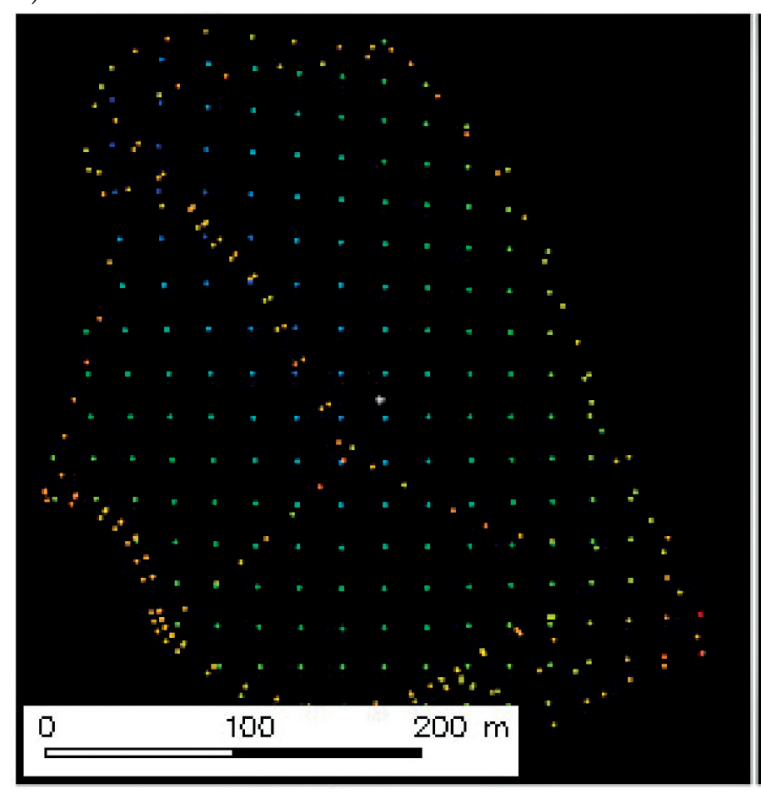

b)

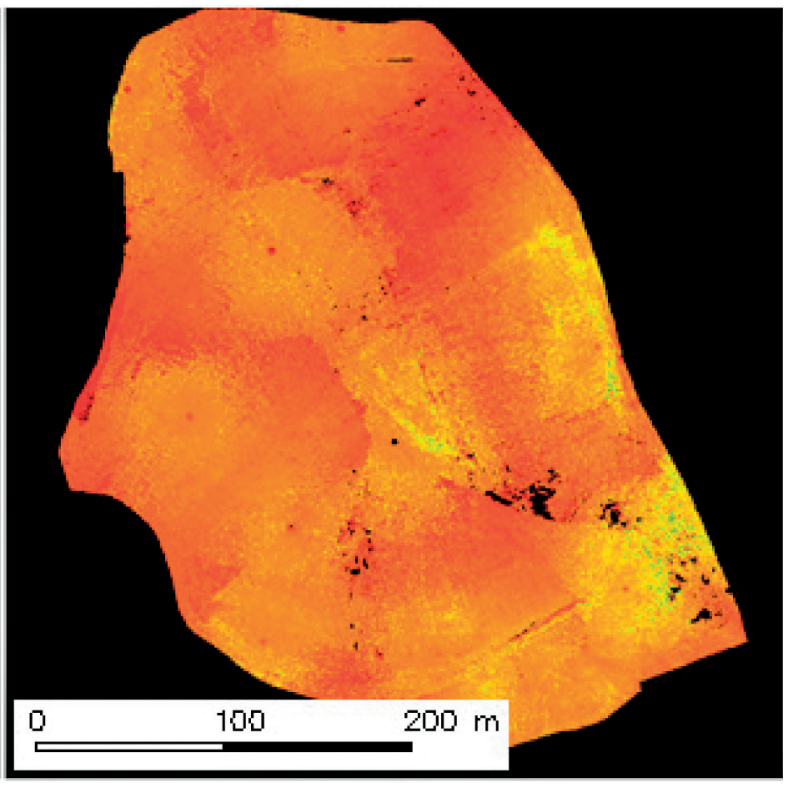

Fig. 6. Visual comparison of point clouds of the semi-coke landfill ash-hill: a) point cloud with the average step of 20 meters, points that stand apart from the regular grid are added breakpoints of landscape (such as the top and the foot of the hill); b) cleaned initial TLS point cloud

Note: Different colours represent the intensity of the reflected TLS signal.

a)

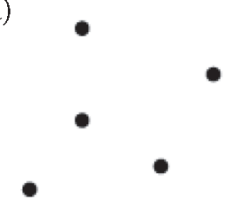

b)

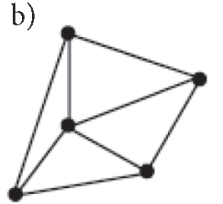

c)

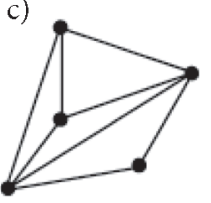

d)

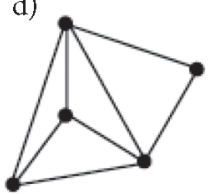

Fig. 7. Different triangle networks created by the same initial data (a), whereas b, c, and d are different results depending on the placement of the triangles ( $\mathrm{Li}$ et al. 2005)

A DEM is an array of square/rectangular shaped cells (pixels) with an elevation value associated to each pixel (Peralvo 2004).

Alternatively, a TIN surface model consists of triangles of which the vertices represent the measurement points. The latter means that the sides of these triangles may have different lengths. The heights of the vertices and the shapes of the triangles in the irregular network may vary (Fig. 7). Although a TIN model can give a better representation of the surface (therefore allowing a slightly more accurate surface model) it requires more complex calculations than raster DEM models (Jagomägi 1999).

These two methods were tested for modelling the surface. Since the TIN models (created by using Autocad Civil 3D package) yielded a slightly better agreement with the initial TLS point cloud, then in further comparisions the TIN modelling results are used.

Comparison of the initial TLS-based surface model with the 10 and $20 \mathrm{~m}$ step surface models yielded relatively small elevation differences, mainly ranging within $\pm 0.5 \mathrm{~m}$ only. For instance, the $10 \mathrm{~m}$ step model surface heights vary (with respect to the initial TLS model) within the range of $\pm 0.20 \mathrm{~m}$ over $98 \%$ of the total area (see Table 2).

Table 2. The comparison results of surface models

\begin{tabular}{|l|c|c|c|c|c|}
\hline & $\begin{array}{c}\text { Cleaned } \\
\text { TLS point } \\
\text { cloud }\end{array}$ & \multicolumn{4}{|c|}{\begin{tabular}{c}
\multicolumn{3}{|c|}{ Thinned point clouds (including } \\
breakpoints)
\end{tabular}} \\
\hline $\begin{array}{l}\text { Average steps } \\
\text { between } \\
\text { points [m] }\end{array}$ & 0.5 & 10 & 20 & 30 & 50 \\
\hline $\begin{array}{l}\text { Ratio of } \\
\text { discrepancies } \\
\text { within } \\
\pm 0.20 \mathrm{~m} \text { [\%] }\end{array}$ & - & 98.03 & 92.00 & 68.83 & 49.84 \\
\hline $\begin{array}{l}\text { RMSE } \\
\text { values, unit } \\
\text { is metre/no. } \\
\text { of points }\end{array}$ & $-/ 130393$ & 1178 & 420 & 305 & 173 \\
\hline
\end{tabular}


The similar comparison with the $20 \mathrm{~m}$ point step resulted in height discrepancies within the range of $\pm 0.20 \mathrm{~m}$ over $82 \%$ of the total area (see Table 2). Apparently, the $20 \mathrm{~m}$ surveying step is also capable to represent the landscape rather accurately.

Comparing the TLS surface model with the $30 \mathrm{~m}$ step surface model (Figs 8a, 9) revealed smaller height discrepancies (within the range of $\pm 0.20 \mathrm{~m}$ ) over only of $69 \%$ of the total area (see Table 2). However, $97 \%$ of height differences remain still within the range of $\pm 0.50 \mathrm{~m}$.

Considerably larger differences emerged when comparing the TLS data with the $50 \mathrm{~m}$ step surface model (Figs $8 \mathrm{~b}, 10$ ). The comparison showed that only $50 \%$ of the height differences were within the range of $\pm 0.20 \mathrm{~m}$ (see Table 2), whereas the maximum difference reached as much as $2.50 \mathrm{~m}$. This shows that the $50 \mathrm{~m}$ surveying step is not precise enough to represent the landscape accurately.

It can be (somewhat expectedly) concluded that large data steps may yield large height discrepancies.
It is acknowledged that the selected surface modelling method contributes insignificantly to the detected discrepancies.

In addition to histograms also root mean square errors (RMSE) were calculated for all the thinned surfaces:

$$
R M S E=\sqrt{\frac{\sum_{1}^{n} \theta_{i}^{2}}{n}},
$$

where $\theta$ is the true error (deviation from a real value), $n$ is the number of measurements (in this case the number of thinned points) and $i=1,2,3, \ldots, n$.

In this work TLS data was used to create a reference surface for calculating RMSE values for thinned surfaces. The calculated root mean square error (RMSE) values between the TLS surface model and the surface models created from average point step of 10 , 20, 30 and $50 \mathrm{~m}$ are presented in Table 2.

The table reveals that only the $10 \mathrm{~m}$ data step is able to ensure the required heighting accuracy $10 \mathrm{~cm}$

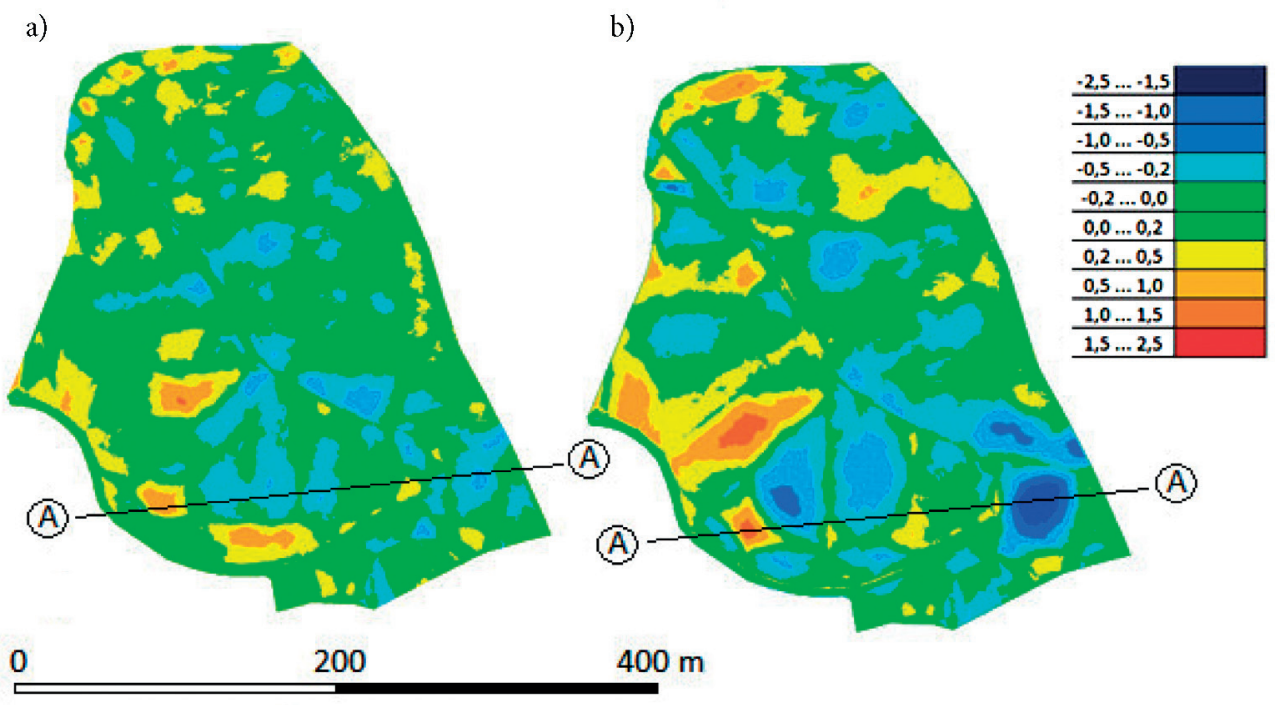

Fig. 8. The comparison models of TLS data and the imitated tacheometric data with the $30 \mathrm{~m}$ (left) and $50 \mathrm{~m}$ (right) data step

Notes: Cooler colours illustrate areas where TLS surface model is above the thinned model. Cross section A-A is explained on Figure 11.

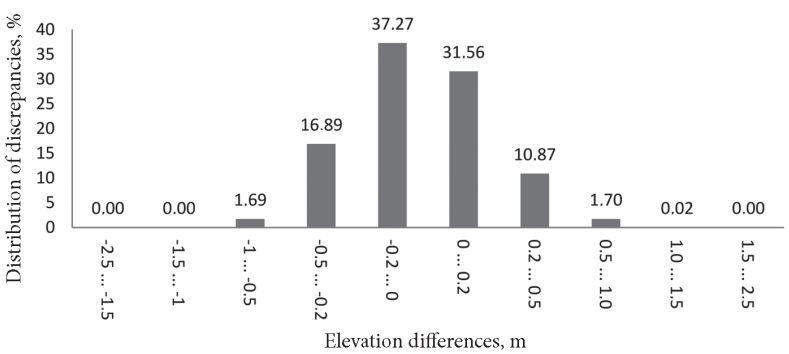

Fig. 9. Histogram illustrating the elevation discrepancies between TLS surface model and the $30 \mathrm{~m}$ step surface model

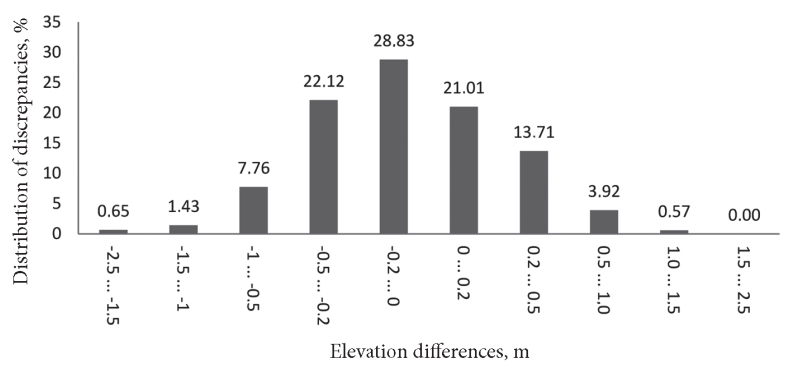

Fig. 10. Histogram illustrating the elevation discrepancies between TLS surface model and the $50 \mathrm{~m}$ step surface model 
in M 1:500 scale topographic surveys. The $20 \mathrm{~m}$ data step can be considered for fulfilling the heighting accuracy requirements $(15 \mathrm{~cm})$ for the M 1:1000 topographic surveys, whereas the $30 \mathrm{~m}$ data step fulfils the heighting accuracy requirements $(20 \mathrm{~cm})$ for the M 1:2000 topographic surveys.

Therefore, it can be concluded that heighting error values set by national standards are somewhat too optimistic. For example the calculated error values for $50 \mathrm{~m}$ data step (as suggested by the Surveying regulation 2007) is not suitable for satisfying the heighting accuracy requirements posed for the 1:1000 and 1:2000 scale surveys. Accordingly, considering the calculated RMSE values and the maximum allowable elevation errors (Estonian national standard for land survey) for scales 1:500, 1:1000 and 1:2000 an average survey step of $10 \mathrm{~m}$ for a scale of 1:500 should be used instead of 20 meters stated by the standard. For scales 1:1000 and 1:2000 an average measurement step of 20 $\mathrm{m}$ is recommended instead of $30 \mathrm{~m}$ and $50 \mathrm{~m}$ stated in the standard, respectively.
It should be noted though, that this particular landform has significant relative height differences. Accordingly, in more flat landscapes the data step selection can be more relaxed. On the other hand the test area had a rather smooth and homogeneous slopes, thus it can be assumed that on a more complex and rugged landscape the heighting errors would be even larger than they were detected during the course of this study. All in all, this appears to be evidence, that existing national survey regulations should not be followed blindly, since more complicated areas and landforms may require development of specific topographic surveying methods.

\subsection{Comparison of longitudinal profiles}

In order to assess the longitudinal height discrepancies cross profile were created across the ash-hill area with the largest discrepancies (Profile A-A, cf. Fig. 8).

The resulting profiles of surfaces compiled from the 10 and $20 \mathrm{~m}$ data steps agree reasonably with the TLS surface (Fig. 11). The maximum discrepancies remain within the range of $\pm 30 \mathrm{~cm}$.
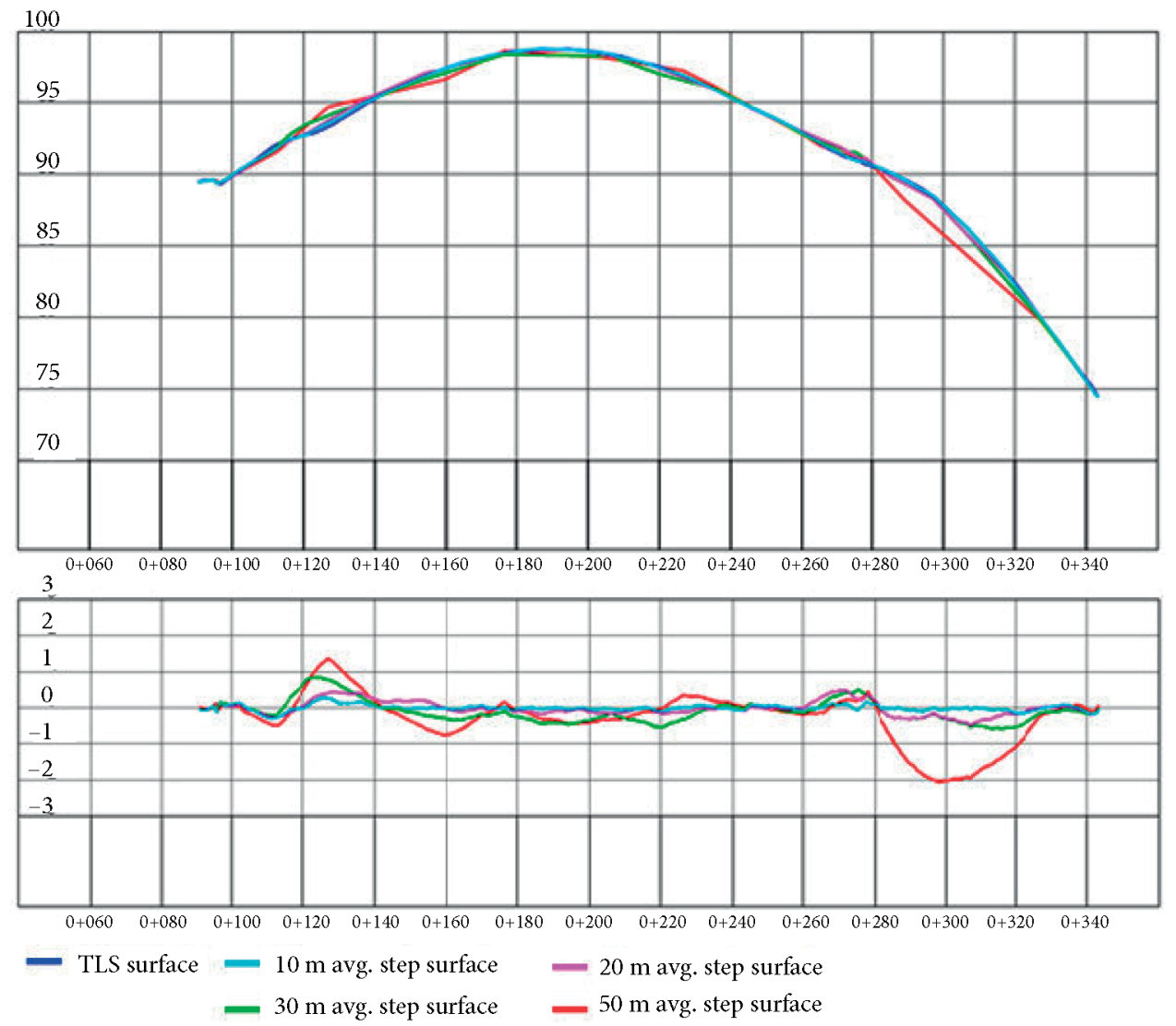

Fig. 11. Top: cross profiles A-A of the landfill ash-hill.

Bottom: discrepancies of profiles A-A compared to TLS surface model of the landfill ash-hill

Notes: Notice that the vertical scale of the TOP figure is 4 times exaggerated compared that of the horizontal scale. Notice that the vertical scale of the BOTTOM figure is 10 times exaggerated as compared to that of the horizontal scale. 
Larger differences are associated with the profiles created for the 30 and $50 \mathrm{~m}$ data step surfaces. For instance the $50 \mathrm{~m}$ profile height discrepancies (with respect to the TLS surface) reach up to $2 \mathrm{~m}$, cf. the section $0+280 \ldots 0+320$ in Figure 11. Note that discrepancies arise smoothly, thus describing a realistic situation where the smooth curvature of the landscape can easily be missed during fieldworks.

Summarizing, the discrepancies of the 10 and $20 \mathrm{~m}$ data step surface models with respect to the TLS based model were mainly caused by several factors: i) the curvature of the tip of the hill ii) slopes iii) concavities on the foot of the hill, cf. Figures 8 (blue tones represent curvatures and orange tones represent concavities) and 11. All of these factors cause generalization errors in surface models and also affect subsequent volume estimations.

\subsection{Volume estimation}

TLS related volume estimates have been reported in Pflipsen (2006), where tacheometric survey data was compared with TLS survey data. Another study by Bremer and Sass (2012) combined ALS and TLS for quantifying sediment volume by a major debris flow event of a steep mountain slope. Mill et al. (2011) compared TLS data and tacheometric data at a road section in order to quantify the volumetric differences. Determining volume differences between surfaces created from different point step data was also one of the goals of this study.

Recall that larger height discrepancies occurred at locations of the smooth curvatures (e.g. long slopes, as opposed to landscape breaklines, where the data is acquired more densely) of the surfaces.

According to the general requirements for mining survey in Estonia (Mine surveying regulation 2012), a volume estimate for mineral resources cannot differ more than $2 \%$ from the actual volume of the excavated material.

Volume calculations were carried out using $\mathrm{Au}-$ todesk Autocad Civil 3D 2013. The reference absolute height for volume calculation was selected to be $67.00 \mathrm{~m}$, which was the lowest point of the surface models created. The maximum absolute height of the ash hill was just under $135.00 \mathrm{~m}$. The volumetric differences between the models created in this work were relatively small, ranging to a maximum of $0.23 \%$ (Table 3). Thus, in this case all the differences are clearly within the required limits. However, when dealing with significantly smaller landforms the volumetric requirements are more difficult to meet. The study showed that the total volume is underestimated when increasing the distance between surveying points. The volumetric differences in Table 2 show that even with a slight change in volume at the large semi-coke landfill ash-hill results in hundreds of truckloads with the average load capacity of $7 \mathrm{~m}^{3}$.

In other words, the higher density of surveying points allows to adequately estimate the actual volume of the earthworks, therefore providing more accurate data that results in efficient work planning.

\section{Concluding remarks}

This study assessed generalization errors that may occur during conventional tacheometric or GNSS survey. TLS survey results over a large area were used for numerical verifications. It was determined, that the 10 and $20 \mathrm{~m}$ data step surface models yield discrepancies within $\pm 20 \mathrm{~cm}$, whereas the $30 \mathrm{~m}$ data step models revealed slightly larger differences. Expectedly the largest elevation differences reaching up to $2.5 \mathrm{~m}$ were associated with the $50 \mathrm{~m}$ point step. It became

Table 3. Results of volumetric calculations on the example of semi-coke landfill ash-hill

\begin{tabular}{|l|c|c|c|c|c|}
\hline Statistical characteristics & $\begin{array}{c}\text { TLS based } \\
\text { surface model }\end{array}$ & $\begin{array}{c}10 \mathrm{~m} \text { data step } \\
\text { surface model }\end{array}$ & $\begin{array}{c}20 \mathrm{~m} \text { data step } \\
\text { surface model }\end{array}$ & $\begin{array}{c}30 \text { m data step } \\
\text { surface model }\end{array}$ & $\begin{array}{c}50 \text { m data step } \\
\text { surface model }\end{array}$ \\
\hline $\begin{array}{l}\text { Volume with respect to } \\
\text { the reference absolute } \\
\text { height }(\mathrm{H}=67,00 \mathrm{~m})\left[\mathrm{m}^{3} \text { ] }\right.\end{array}$ & 2633813.99 & 2633542.14 & 2632789.75 & 2632099.34 & 2627688.45 \\
\hline $\begin{array}{l}\text { Volumetric difference } \\
\text { with respect to TLS } \\
\text { surface model [\%] }\end{array}$ & - & -0.01 & -0.04 & -0.07 & -0.23 \\
\hline $\begin{array}{l}\text { Volumetric difference } \\
\text { with respect to TLS } \\
\text { surface model [m }{ }^{3} \text { ] }\end{array}$ & - & -271.85 & -1024.24 & -1714.65 & -6125.54 \\
\hline $\begin{array}{l}\text { Difference in truckloads } \\
\left(7 \mathrm{~m}^{3} \text { each) }\right.\end{array}$ & - & 39 & 146 & 245 & 875 \\
\hline
\end{tabular}


also evident that existing national survey regulations should not be followed blindly, since more complicated areas and landforms may require development of specific topographic surveying methods. TLS proved to be more beneficial when surveying more complex terrain with steep slopes and other irregularities. If the terrain includes vegetation then TLS data can be easily distorted, since most TLS devices record only one echo of the backscattered laser signal, it is difficult to determine the actual ground surface underneath vegetation. Thus, in the vegetated areas the TLS becomes unsuitable for topographic surveys.

As for determining surface volumes of artificial hills, construction etc. TLS is highly suitable. In this case high density of points causes the error in volume computation to be marginal.

Choosing a survey technology for measuring landscape should be based on the speed and cost effectiveness of the technology as well as the amount of vegetation. For surveying of open field (i.e. without trees and bushes) artificial landscape the most costeffective method would be GNSS survey. GNSS leaves out the additional time spent on orientation of the surveying instrument which is needed in tacheometry and TLS. In addition the cost of the surveying equipment and the required special software for data post processing can be a crucial influence in choosing the suitable technology. Finally when it comes to choosing the most optimum surveying technology the specific nature of the particular object and the resources available should also be considered.

\section{Acknowledgements}

Part of this research is supported by the Estonian Environmental Technology R\&D Programme KESTA research project ERMAS AR12052.

\section{References}

Arun, P. V. 2013. A comparative analysis of different DEM interpolation methods, The Egyptian Journal of Remote Sensing and Space Science 16: 133-139. http://dx.doi.org/10.1016/j.ejrs.2013.09.001

Baltsavias, E. P. 1999. Airborne laser scanning: basic relations and formulas, Journal of Photogrammetry \& Remote Sensing 54: 199-214. http://dx.doi.org/10.1016/S0924-2716(99)00015-5

Bremer, M.; Sass, O. 2012. Combining airborne and terrestrial laser scanning for quantifying erosion and deposition by a debris flow event, Geomorphology 138: 49-60. http://dx.doi.org/10.1016/j.geomorph.2011.08.024

Estonian National Land Board. 2014. Ortophoto. [Online], [cited 12 April 2014]. Available from Internet: http://xgis. maaamet.ee/xGIS/XGis
Fekete, S.; Diederichs, M.; Lato, M. 2010. Geotechnical and operational applications for 3-dimensional laser scanning in drill and blast tunnels, Tunnelling and Underground Space Technology 25: 614-628. http://dx.doi.org/10.1016/j.tust.2010.04.008

Gallay, M.; Lloyd, C. D.; McKinley, J.; Barry, L. 2012. Assessing modern ground survey methods and airborne laser scanning for digital terrain modelling: a case study from the Lake District, England, Computers \& Geosciences 51: 216227. http://dx.doi.org/10.1016/j.cageo.2012.08.015

Geo S.T. OÜ. Archives. 21M2105 Terrestrial laser scanning of Kiviõli ash-hill (in Estonian: Tuhamäe mõõdistamine laserskaneerimise meetodil), unpublished.

Jagomägi, T. 1999. GIS for the practitioner (in Estonian: Geoinfosüsteemid praktikule). Tartu.

Julge, K.; Ellmann, A.; Gruno, A. 2014. Performance analysis of freeware filtering algorithms for determining ground surface from airborne laser scanning data, Journal of Applied Remote Sensing 8(1): 083573-1 - 083573-15. http://dx.doi.org/10.1117/1.JRS.8.083573

Jürgens, A. 2011. Industrial waste and semi-closure of landfills in Kohtla-Järve and Kiviõli (in Estonian: Tööstusjäätmete ja poolkoksi prügilate sulgemine Kohtla-Järvel ja Kiviõlis) [online], [cited 10 April 2014]. Available from Internet: http:// www.envir.ee/1172371

Lempzi pildiblog. 2014. [Online], [cited 11 November 2014]. Available from Internet: https://lempz.wordpress.com/2009/08/

Li, Z.; Zhu, Q.; Gold, C. 2005. Digital terrain modelling principles and methodology. Washington: CRC Press.

Mill, T.; Alt, A.; Liias, R. 2013. Combined 3D building surveying techniques - terrestrial laser scanning (TLS) and total station surveying for BIM data management purposes, Journal of Civil Engineering and Management 19: S23-S32. http://dx.doi.org/10.3846/13923730.2013.795187

Mill, T.; Ellmann, A.; Aavik, A.; Horemuz, M.; Sillamäe, S. 2014. Determining ranges and spatial distribution of road frost heave by terrestrial laser scanning, The Baltic Journal of Road and Bridge Engineering 9(3): 227-236.

Mill, T.; Ellmann, A.; Kiisa, M.; Idnurm, J.; Idnurm, S.; Horemuz, M.; Aavik, A. 2015. Geodetic monitoring of bridge deformations occurring during static load testing, The Baltic Journal of Road and Bridge Engineering 10(1).

Mill, T.; Ellmann, A.; Uueküla, K.; Joala, V. 2011. Road surface surveying using terrestrial laser scanner and total station technologies, in Proceedings from Environmental Engineering, The 8th International Conference, 19-20 May 2011, Vilnius, Lithuania, 1142-1147.

Mine surveying regulation. 2012. Ministry of Economic Affairs and Communications of Republic of Estonia, decree no. 70, 27 August 2007 [online], [cited 20 April 2014]. Available from Internet: https://www.riigiteataja.ee/akt/125012012004

Murphy, M.; McGovern, E.; Pavia, S. 2011. Historic building information modelling - adding intelligence to laser and image based surveys, in Proc. of the ISPRS Workshop 3DARCH, 2-4 March 2011, Trento, Italy.

Naumann, M.; Geist, M.; Bill, R.; Niemeyer, F.; Grenzdörffer, G. 2013. Accuracy comparison of digital surface models created by unmanned aerial systems imagery and terrestrial laser scanner, in International Archives of the Photogrammetry, Remote Sensing and Spatial Information Sciences, XL-1/W2, 4-6 September 2013, Rostock, Germany, 281-286. http://dx.doi.org/10.5194/isprsarchives-XL-1-W2-281-2013 
Nuttens, T.; Wulf, A.; Bral, L.; Wit, B.; Carlier, L.; Ryck, M.; Stal, C.; Constales, D.; Backer, H. 2010. High resolution terrestrial laser scanning for tunnel deformation measurements, in FIG Congress 2010, Facing the Challenges - Building the Capacity, 11-16 April 2010, Sydney, Australia

Pae, T.; Luud, A.; Sepp, M. 2005. Artificial mountains in northeast Estonia: monumental dumps of ash and semi-coke, Journal Oil Shale 22: 333-343.

Peralvo, M. 2004. Influence of DEM interpolation methods in drainage analysis. GIS Hydro 04 Texas, USA.

Pflipsen, B. 2006. Volume computation - a comparison of total station versus laser scanner and different software: Master's Thesis. University of Gävle.

Pirotti, F.; Guarnieri, A.; Vettore, A. 2013. State of the art of ground and aerial laser scanning technologies for high-resolution topography of the Earth surface, European Journal of Remote Sensing 46: 66-78. http://dx.doi.org/10.5721/EuJRS20134605

Surveying regulation. 2007. Ministry of Economic Affairs and Communications of Republic of Estonia, decree no. 70, 27 August 2007 [online], [cited 10 April 2014]. Available from Internet: https://www.riigiteataja.ee/akt/125012012004

Vosselman, G.; Maas, H.-G. 2009. Airborne and terrestrial laser scanning. Dunbeath: Whittles publisher. 320 p. ISBN 9781439827987

Wang, T.-T.; Jaw, J.-J.; Chang, Y.-H.; Jeng, F.-S. 2009. Application and validation of profile-image method for measuring deformation of tunnel wall, Tunnelling and Underground Space Technology 24: 136-147.

http://dx.doi.org/10.1016/j.tust.2008.05.008
Martin SOBAK received his MSc degree in geodesy from the Tallinn University of Technology (TUT, Estonia) in 2014. Currently he is 3D Laser Scanning specialist in surveying enterprise Geo S.T. OÜ. His main research interest are engineering geodesy and remote sensing by methods of terrestrial laser scanning.

Artu ELLMANN received his MSc degree in geodesy from the Moscow State University of Geodesy and Cartography (formerly MIIGAiK) in 1993 and a PhD degree from the Royal Institute of Technology (KTH) in Stockholm in 2004. He is currently Professor in Geodesy at the Department of Road Engineering, Faculty of Civil Engineering at the TUT. National correspondent to the International Association of Geodesy (IAG) since 2006. His research interests include remote sensing, physical geodesy (gravity field and geoid modelling in particular), engineering surveying.

Tarvo MILL received his MSc degree in transport engineering and logistics from the Tallinn University of Technology (TUT, Estonia) in 2008. He is currently a Early Stage Researcher Geodesy at the Department of Road Engineering, Faculty of Civil Engineering at the TUT. Lecturer at University of Applied Science (UAS), Faculty of Construction, the Chair of Construction Geodesy. Also pursuing postgraduate studies towards $\mathrm{PhD}$ degree in civil engineering (geodesy) at the TUT. Author of scientific publications. Participated in a few international conferences. Research interests: terrestrial laser scanning, engineering surveying. 